\title{
Non-Invasive Hemodynamic Assessment of Non-pregnant, Healthy Pregnant and Preeclamptic Women using Bio-Reactance
}

\author{
Yayoi Ohashi ${ }^{1}$, Hisham Ibrahim ${ }^{2}$, Louis Furtado ${ }^{3}$, John Kingdom ${ }^{4}$, Jose Carlos Almeida Carvalho ${ }^{5}$
}

Summary: Ohashi Y, Ibrahim H, Furtado L, Kingdom J, Carvalho JCA - Non-Invasive Hemodynamic Assessment of Non-pregnant, Healthy Pregnant and Preeclamptic Women using Bio-Reactance.

Background and objectives: We compared hemodynamic profiles of healthy and mildly preeclamptic pregnant women at term, as well as those of non-pregnant controls, using a new non-invasive cardiac output monitor (NICOM) based on bio-reactance.

Methods: We studied healthy term pregnant women at term (Preg, $n=10$ ), mildly preeclamptic pregnant women at term $($ PregPE, $n=10)$, and healthy non-pregnant female volunteers (NonPreg, $n=10$ ). With the subjects in the semi left lateral position, 4 electrodes of the NICOM device were applied to their chest wall, followed by a 15-minute rest period. Hemodynamic variables, including the systolic (SBP), diastolic (DPB) and mean arterial (MAP) pressures, as well as the heart rate (HR), stroke volume (SV), total peripheral resistance (TPR), cardiac output (CO), cardiac power output (CPO), and ventricular ejection time (VET) were then monitored for 15 minutes.

Results: The Preg and NonPreg groups showed similar hemodynamic profiles, except for a shorter VET in the Preg group (213.3 \pm 19.3 ms versus $265.0 \pm 28.8 \mathrm{~ms}, \mathrm{p}<0.001)$. The PregPE group showed higher SBP, DBP and MAP, as well as CPO $(145.5 \pm 12.6 \mathrm{mmHg} ; 94.5 \pm 9.1$ $\mathrm{mmHg} ; 111.5 \pm 9.8 \mathrm{mmHg} ; 1.6 \pm 0.3$ watts $)$, compared to both the Preg $(114 \pm 12.1 \mathrm{mmHg} ; 71.7 \pm 8.4 \mathrm{mmHg} ; 85.9 \pm 9.3 \mathrm{mmHg} ; 1.1 \pm 0.3$ watts $)$ and NonPreg $(101.2 \pm 11.9 \mathrm{mmHg} ; 66.7 \pm 10.4 \mathrm{mmHg} ; 78.1 \pm 10.6 \mathrm{mmHg} ; 1.0 \pm 0.2$ watts $)$ groups. The PregPE group showed higher HR, CO, and TPR, and shorter VET (85.4 \pm 8.4 beats. min $^{-1} ; 6.6 \pm 0.7$ L. min $^{-1} ; 1,369.9 \pm 173.5$ dyne.sec.cm ${ }^{-5}, 221.6 \pm 22.4$ ms $)$ compared to the NonPreg group $\left(67.9 \pm 9.5\right.$ beats. $\mathrm{min}^{-1} ; 5.6 \pm 0.7$ L. $\mathrm{min}^{-1} ; 1,136.9 \pm 149.8$ dyne.sec.cm $\left.{ }^{-5}, 265.0 \pm 28.8 \mathrm{~ms}\right)$.

Conclusions: The NICOM device is simple to use, operator independent, and provides clear and consistent monitoring signals. The output identified distinct hemodymamic profiles that are consistent with the findings of more invasive existing methods.

Keywords: PHYSIOLOGY, Cardiovascular; HEMODYNAMICS; MONITORING, bioreactance technology, physiological; PREGNANCY, preeclampsia.

Cheeta Medical provided the equipment for research.

[Rev Bras Anestesiol 2010;60(6): 603-613] @Elsevier Editora Ltda.

\section{INTRODUCTION}

Invasive hemodynamic techniques have long identified significant increases in heart rate (HR), blood volume (BV), left ventricular end-diastolic volume (LVEDV), stroke volume (SV) and cardiac output (CO) during the first and second trimesters of pregnancy ${ }^{1,2}$. Despite these changes, maternal blood pressure still falls due to a large reduction in the total peripheral resistance (TPR) from systemic vasodilation and the formation of a low-resistance uteroplacental circulation.

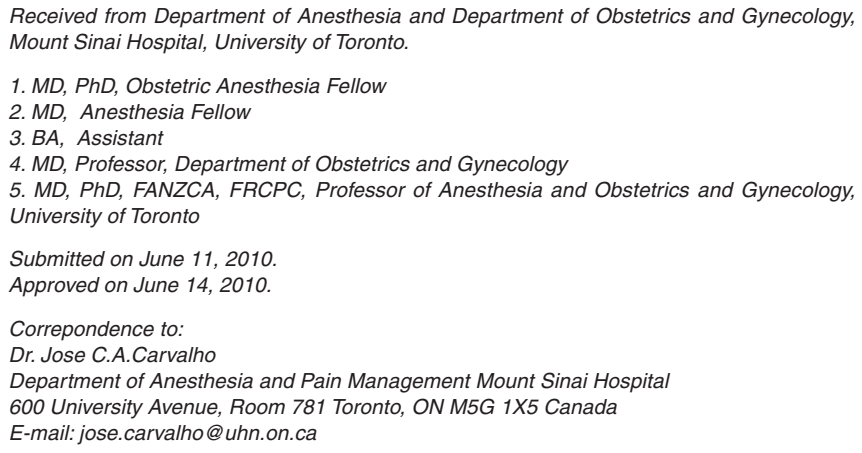

In the last trimester of pregnancy, however, this profile changes, due in part to the fully developed fetus gradually obstructing venous return via the inferior vena cava. The cardiac output then decreases and the total vascular resistance increases; the systolic (SBP), diastolic (DBP) and mean (MAP) arterial blood pressures also increase ${ }^{2}$.

Maternal hemodynamic changes can be further complicated by preeclampsia, which occurs in $6 \%-12 \%$ of all pregnancies 3,4 . Preeclampsia has always been found to show varied hemodynamic profiles, making it difficult for the clinician to plan a goaldirected management or therapy plan ${ }^{5,6}$. It has recently been suggested that preeclampsia can be established earlier $(<34$ weeks) or later (> 34 weeks) in pregnancy, and that these two entities have different etiologies and should be considered different forms of the disease ${ }^{7,8}$. It has also been shown that during their latent phases, early and late preeclampsia show two very different maternal hemodynamic profiles, including high TPR in the former versus low TPR in the latter ${ }^{9}$.

With such dramatic hemodynamic changes during the course of pregnancy, both healthy and high risk pregnant women would benefit from a routine, non-invasive, operator-independent cardiovascular assessment during their 
prenatal care, beyond the classic arterial blood pressure. A meticulous hemodynamic assessment throughout pregnancy might revolutionize prenatal care, allowing early diagnosis of high risk patients and the use of goal-directed therapies.

Most of the available data on hemodynamic changes in healthy and high risk pregnancies has been generated by studies using pulmonary artery catherization, still considered the gold standard for central hemodynamic monitoring $2,10,11$. The technique, however, carries many risks and disadvantages, and has limited use in obstetrics ${ }^{12}$. More recently, minimally-invasive techniques based on arterial pulse waveform analysis methods have been validated against pulmonary artery catherization in non-obstetric patients. Currently available methods, each based on a different algorithm, include the LiDCOplus (LiDCO, Cambridge, United Kingdom), the PiCCOplus (Pulsion Medical Systems, Munich,Germany), and the Vigileo (Edwards Lifesciences, Irvine, CA). They have all been used with some success in the obstetric patient, but again, they require the use of a peripheral arterial line ${ }^{13}$.

There is no question that non-invasive monitoring is a highly desirable resource in obstetric medicine. Impedance cardiography ${ }^{14}$, thoracic electrical bioimpedance ${ }^{15}$, and transthoracic echocardiography ${ }^{16}$ have all been validated against pulmonary artery catherization in the obstetric population. All of these methods have limitations including the requirement for user education and an interference of movement artifact. Transthoracic bioimpedance was the first non-invasive method used for $\mathrm{CO}$ monitoring, and it has been used in many obstetric settings ${ }^{17}$. Although it has the advantage of being operator-independent, its use is limited because of questionable accuracy, perhaps due to a low signal-to-noise ratio. Also, variations in patient body habitus and other physical factors impact on the electrical conductivity between the electrodes and skin ${ }^{18}$.

Transthoracic bio-reactance is a newer technique used for non-invasive continuous cardiac output monitoring ${ }^{19}$. It is based on the frequency-modulation and phase-modulation of the voltage signal measured in response to an applied transthoracic current. The phase shifts are measured continuously, and have been shown to relate almost linearly to blood flow in the aorta. The bio-reactance technique offers a significant advantage in filtering noise, and provides an improved signal-to-noise ratio compared to bio-impedance. Moreover, its readings were shown to correlate well with the results of pulmonary artery catheter derived measurements of cardiac output ${ }^{20}$. It has been shown that the non-invasive cardiac output measurement (NICOM) system, which uses bio-reactance technology, has acceptable accuracy, precision and responsiveness for $\mathrm{CO}$ monitoring in patients experiencing a wide range of circulatory situations ${ }^{21}$. The NICOM has not been used for hemodynamic assessment and monitoring in pregnant women.

This study was designed to compare the hemodynamic profiles of healthy and mildly preeclamptic pregnant women at term, as well as those of non pregnant women using the NICOM.

\section{METHODS}

After institutional research ethics board approval and written informed consent, three groups of women ( $n=10$ in each group) were recruited into this prospective, open, comparative study. All subjects were between 18 and 40 years of age and able to communicate in English, and belonged to one of the three following categories: a) healthy pregnant women at term (Preg); b) pregnant women at term with newly diagnosed, untreated preeclampsia (PrePE) who were documented to have had normal pressure on at least 2 occasions before 20 weeks of gestation; and c) non-pregnant healthy female volunteers (NonPreg). All pregnancies were singleton and the patients were not in labor. Pregnant women with pre-existing diseases such as insulindependent diabetes, chronic hypertension, and auto-immune, cardiovascular or renal diseases were excluded.

Preeclampsia was defined by The American College of Obstetricians and Gynecologists (ACOG) criteria as newly diagnosed systolic blood pressure of at least $140 \mathrm{mmHg}$ or diastolic blood pressure of $90 \mathrm{mmHg}$ on at least 2 occasions; the measurements had to be taken at least 4 hours but not more than 7days apart.

A bio-reactance-based non-invasive cardiac output monitoring system (NICOM ${ }^{\mathrm{TM}}$, Cheetah Medical Inc, Portland, OR) was used in this study. Participants were asked to rest in the left semi-lateral decubitus position for 15 minutes after the placement of 4 electrodes on their thorax, and automatic calibration of the NICOM system. Additionally, a non-invasive blood pressure cuff was applied to the left arm and connected to the monitoring system. Automated blood pressure measurements were taken every minute by the NICOM internal blood pressure monitoring system throughout the study.

The following cardiovascular variables were assessed continuously for 15 minutes to define baseline values: systolic blood pressure (SBP), diastolic blood pressure (DBP), mean arterial pressure (MAP), heart rate $(\mathrm{HR})$, cardiac output $(\mathrm{CO})$, cardiac power output (CPO), stroke volume (SV), ventricular ejection time (VET), and total peripheral resistance (TPR). Following this 15-minute monitoring period during which the patient was at rest, a passive leg raising (PLR) test was performed. The hemodynamic variables were measured with the patient lying on the bed in a left semi-lateral decubitus position for 3 minutes and then with the subject's legs raised to 45 degrees for 3 minutes.

Continuous data are expressed as a mean \pm standard deviation. Differences between the groups were compared with T-tests, with $p$-values corrected for multiple comparisons by the Bonferonni procedure. The effect of the PLR test was determined by comparing the percent change in each variable from baseline, following the leg raise, using a 2-tail T-test. Differences were considered significant when $p<0.05$. All the statistical analyses were performed using Excel software.

\section{RESULTS}

The patients' characteristics are summarized in Table I. Pregnant patients, both healthy and preeclamptic, had a higher $\mathrm{BMI}$ as compared to non-pregnant patients. 
The hemodynamic variables for all the groups are summarized in Table II. Healthy pregnant women demonstrated shorter VETs compared to non-pregnant women $(213.0 \pm 19.3 \mathrm{~ms}$ versus $265.0 \pm 28.8 \mathrm{~ms}, \mathrm{p}<0.001)$. All the other variables were similar between these two groups.

Preeclamtic women showed higher SBP, DBP, MAP and CPO compared to healthy pregnant women $(p<0.001)$.
Preeclamptic women showed higher HR $(p<0.001)$, SBP $(p<0.001)$, DBP $(p<0.001)$, MAP $(p<0.001)$, CPO $(p<$ $0.001)$, TPR $(p=0.014)$ and CO $(p=0.013)$, but shorter VET $(p<0.001)$ compared to non-pregnant women.

The percent changes in the hemodynamic variables after the PLR tests are summarized in Table III. There were no significant differences between the three groups.

Table I - Patients' Characteristics

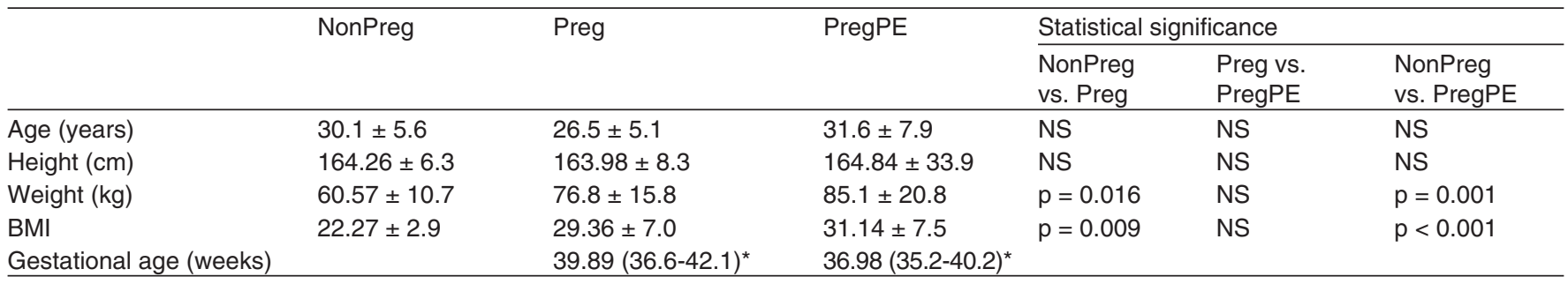

NonPreg: non-pregnant women, Preg: healthy pregnant women, PregPE: mildly preeclamptic pregnant women, BMI: body mass index, NS: not significant; Data are presented as mean \pm standard deviation. * Mean and range

Table II - Hemodynamic Data

\begin{tabular}{|c|c|c|c|c|c|c|}
\hline & \multirow[t]{2}{*}{ NonPreg } & \multirow[t]{2}{*}{ Preg } & \multirow[t]{2}{*}{ PregPE } & \multicolumn{3}{|c|}{ Statistical significance } \\
\hline & & & & $\begin{array}{l}\text { NonPreg } \\
\text { vs. Preg }\end{array}$ & $\begin{array}{l}\text { Preg vs. } \\
\text { PregPE }\end{array}$ & $\begin{array}{l}\text { NonPreg } \\
\text { vs. PregPE }\end{array}$ \\
\hline SBP (mmHg) & $101.2 \pm 11.9$ & $114.5 \pm 12.1$ & $145.5 \pm 12.6$ & NS & $p<0.001$ & $p<0.001$ \\
\hline MAP $(\mathrm{mmHg})$ & $78.1 \pm 10.6$ & $85.9 \pm 9.3$ & $111.5 \pm 9.8$ & NS & $p<0.001$ & $p<0.001$ \\
\hline $\mathrm{HR}$ (beats. $\mathrm{min}^{-1}$ ) & $67.9 \pm 9.5$ & $78.8 \pm 11.6$ & $85.4 \pm 8.4$ & NS & NS & $p=0.001$ \\
\hline $\mathrm{CO}\left(\mathrm{L} \cdot \mathrm{min}^{-1}\right)$ & $5.6 \pm 0.7$ & $5.9 \pm 1.1$ & $6.6 \pm 0.7$ & NS & NS & $p=0.013$ \\
\hline SV $\left(m L\right.$. beat $\left.^{-1}\right)$ & $83.3 \pm 12.5$ & $76.4 \pm 17.0$ & $77.7 \pm 7.2$ & NS & NS & NS \\
\hline VET (milliseconds) & $265.0 \pm 28.8$ & $213.3 \pm 19.3$ & $221.6 \pm 22.4$ & $p<0.001$ & NS & $p=0.001$ \\
\hline
\end{tabular}

NonPreg: non-pregnant women, Preg: healthy pregnant women, PregPE: mildly preeclamptic pregnant women, SBP: systolic blood pressure, DBP: diastolic blood pressure, MAP: mean arterial pressure, HR: heart rate, CO: cardiac output, TPR: total peripheral resistance (MAP/CO), CPO: cardiac power output, SV: stroke volume, VET: ventricular ejection time, NS: not significant;

Data are presented as mean \pm standard deviation

Table III - Percent Changes of Hemodynamic Variables with a Passive Leg Raising (PLR) Test

\begin{tabular}{|c|c|c|c|c|c|c|}
\hline & \multirow[t]{2}{*}{ NonPreg } & \multirow[t]{2}{*}{ Preg } & \multirow[t]{2}{*}{ PregPE } & \multicolumn{3}{|c|}{ Statistical significance } \\
\hline & & & & $\begin{array}{l}\text { NonPreg } \\
\text { vs. Preg }\end{array}$ & $\begin{array}{l}\text { Preg vs. } \\
\text { PregPE }\end{array}$ & $\begin{array}{l}\text { NonPreg } \\
\text { vs. PregPE }\end{array}$ \\
\hline $\mathrm{SBP}(\mathrm{mmHg})$ & $5.17 \pm 7.70$ & $1.67 \pm 4.83$ & $1.86 \pm 6.70$ & NS & NS & NS \\
\hline $\mathrm{DBP}(\mathrm{mmHg})$ & $1.01 \pm 9.37$ & $5.34 \pm 6.98$ & $1.49 \pm 8.93$ & NS & NS & NS \\
\hline MAP (mmHg) & $2.8 \pm 7.07$ & $3.86 \pm 5.07$ & $1.80 \pm 6.88$ & NS & NS & NS \\
\hline $\mathrm{HR}$ (beats. $\mathrm{min}^{-1}$ ) & $3.01 \pm 4.14$ & $3.00 \pm 4.21$ & $0.48 \pm 3.87$ & NS & NS & NS \\
\hline $\mathrm{CO}\left(\right.$ L. $\left.\mathrm{min}^{-1}\right)$ & $11.73 \pm 9.70$ & $9.86 \pm 10.86$ & $11.81 \pm 21.58$ & NS & NS & NS \\
\hline TPR (dyne.sec.cm-5) & $-4.54 \pm 9.99$ & $-5.17 \pm 10.06$ & $-3.65 \pm 13.28$ & NS & NS & NS \\
\hline $\mathrm{SV}\left(\mathrm{mL}^{\text {beat }}{ }^{-1}\right)$ & $9.39 \pm 8.21$ & $7.67 \pm 8.90$ & $13.32 \pm 22.02$ & NS & NS & NS \\
\hline SVV $(\%)$ & $20.13 \pm 13.09$ & $26.22 \pm 18.50$ & $11.42 \pm 10.01$ & NS & NS & NS \\
\hline
\end{tabular}

NonPreg: non-pregnant women, Preg: healthy pregnant women, PregPE: mildly preeclamptic pregnant women, SBP: systolic blood pressure, DBP: diastolic blood pressure, MAP: mean arterial pressure, HR: heart rate, CO: cardiac output, TPR: total peripheral resistance, SV: stroke volume, SVV: stroke volume variation, NS: not significant;

Data are presented as mean \pm standard deviation. 


\section{DISCUSSION}

The results of our study confirm existing data on the hemodynamic features of pregnant and non-pregnant women, and also introduce new hemodynamic concepts that may be of interest to clinicians. Our results suggest that bio-reactance may be one step closer to an operator-independent, consistent, simple-to-use, non-invasive monitor that can function as a much needed tool for clarifying the hemodynamics of healthy and high risk pregnancies.

Pregnancy induces significant hemodynamic changes secondary to an increase in plasma volume, a decrease in systemic vascular resistance, and an increase in myocardial performance. These changes are necessary to meet the increasing metabolic demands of pregnancy. They start early in pregnancy, peak at the end of the second trimester, and gradually trend to non-pregnant levels towards term ${ }^{2}$. Specifically, SBP, DBP, MAP and TPR decrease, and SV, HR and $\mathrm{CO}$ increase until mid-pregnancy, then the trend is reversed towards term, except for HR, which tends to remain elevated throughout pregnancy. Most of the reversed trends observed in the third trimester are attributed to the compression of the inferior vena cava, especially when the pregnant woman is in the supine position. It has been shown that aortocaval compression is present in $40 \%$ of supine pregnant women, even when they are tilted between $0^{\circ}-34^{\circ}$, as well as when they are lying in the semi-recumbent position ${ }^{22,23}$.

Our results comparing healthy pregnant women at term with non-pregnant women are consistent with previous data in the literature. We did not find any significant difference in the hemodynamic variables between them, except for a shorter VET in pregnant patients. The left ventricular ejection time (LVET), an index of left ventricular performance, has been shown in previous studies to correlate with ejection fraction and intrinsic cardiac contractility ${ }^{24-26 .}$ This is an interesting new variable that could be explored in future studies, as it may indicate that myocardial performance is increased in healthy pregnant women at term.

The preeclamptic women, however, showed a very distinct hemodynamic profile when compared both with the nonpregnant and healthy pregnant women. When compared to the Preg group, the SBP, DBP, MAP and CPO of the PregPE group were higher. The CPO takes into account both the pressure- and flow-generating capacities of the heart, and provides a more complete representation of the overall cardiac performance. Maximal CPO may be better than maximal $\mathrm{CO}$ and left ventricular stroke work index (SWI) independently in representing cardiac pumping capability ${ }^{26}$. The TPR was not statistically different. These results may suggest that PregPE patients show a hyperdynamic state, in the context of a similar TPR.

When compared with the NonPreg group, the PregPE results are even more remarkable. The SBP, DBP, MAP and CPO were higher in the PregPE group, similar to the previous comparison. However, in the PregPE the HR, CO and TPR were also significantly higher. These results suggest a hyperdynamic state in the PregPE group in the context of an increased TPR.
The apparent discrepancy in findings related to TPR may be a function of the sample size of our study. The trends observed in the Preg and PrePE women were in the same direction, only more remarkable in the preeclamptic patients. These results also suggest that ideally each woman should serve as her own control for her hemodynamic assessment throughout pregnancy.

The passive leg raise (PLR) test has been suggested to predict fluid responsiveness. PLR induces an abrupt increase in preload due to the auto-transfusion of blood from the capacitance veins of the legs to the intrathoracic compartment, leading to an increase in cardiac output in preload-dependent patients. The PLR test has recently been introduced as an essential part of hemodynamic monitoring, since the effects of auto-transfusion on aortic blood flow or cardiac output enable the assessment of fluid responsiveness ${ }^{27,28}$. In this study, however, we did not find any significant difference in the percent changes of the hemodynamic parameters with PLR testing among the three groups, indicating similar fluid responsiveness in all groups.

Recently, both minimally invasive and non-invasive monitoring has received significant attention from investigators and clinicians. A great deal of useful information about the obstetric patient has been gained, but each type of monitoring has its own limitations. The minimally invasive techniques such as PiCCO, LiDCO, and Vigileo still require an arterial line and other procedures that will always be a limiting factor in obstetrics. Hence, high expectations have been placed on non-invasive monitoring techniques. However, some of these methods, such as transthoracic echo and suprasternal Doppler are operator-dependent, which is also a barrier to its implementation.

The totally non-invasive, operator-independent techniques of bioimpedance and bio-reactance are, therefore, where efforts can be directed if we want to have a monitor that will enable further understanding about hemodynamic changes in pregnancy, and the potential utility of goal-directed prevention or therapy for some patients.

Transthoracic bioimpedance (intrabeat measurement of changes in transthoracic voltage amplitude in response to an injected high-frequency current) was the first non-invasive method devised for continuous non-invasive monitoring of cardiac output. It has been used to study the hemodynamic patterns in pregnancy and preeclampsia ${ }^{17}$. Although its clinical use has increased, it is limited in some clinical settings because of a low signal-to-noise ratio which apparently limits its accuracy in environments where there is ambient electrical noise. Also, the technique is sensitive to the placement of the electrodes on the body, variations in patient body size and other physical factors, such as temperature and humidity, that impact on electrical conductivity between the electrodes and skin ${ }^{18}$.

Transthoracic bio-reactance is a newer technique of noninvasive continuous cardiac output monitoring. It is based on an analysis of the relative phase shifts of oscillating currents that occur when the current traverses the thoracic cavity, as opposed to the traditional bioimpedance-based system which relies only on measured changes in the signal amplitude. 
Unlike bioimpedance, bioreactance-based non-invasive $\mathrm{CO}$ measurement does not use static impedance, and does not depend on the distance between the electrodes for the calculations of SV and CO, thereby significantly increasing the accuracy of the result. Moreover, its readings were shown to correlate well with results obtained from the pulmonary artery catheter thermodilution-derived measurements of cardiac output ${ }^{20}$. In addition, it has also been shown that the NICOM system has acceptable accuracy, precision and responsiveness for $\mathrm{CO}$ monitoring in patients experiencing a wide range of circulatory situations ${ }^{21}$.

In summary, the NICOM was simple to use, and provided a very clear and consistent monitoring signal. It identified distinct hemodynamic profiles in the three studied groups that were consistent with previous data. We concluded that the NICOM is a promising non-invasive monitoring system for obstetric patients, and further studies are warranted in laboring and critically ill patients, and those undergoing operative deliveries. We suggest that a monitor such as the NICOM may offer a valuable opportunity to make early diagnoses and provide goal-directed therapy in women with preeclampsia, and other medical conditions that affect women during pregnancy.

\section{ACKNOWLEDGEMENTS}

The authors acknowledge Kristi Downey, Perinatal Research Coordinator, Department of Anesthesia and Pain Management, Mount Sinai Hospital, for facilitating various aspects of this project. 

siol, 2009;22:347-351.

07. von Dadelszen P, Magee LA, Roberts JM - Subclassification of pre-eclamspia. Hypertens Pregnancy, 2003;22:143-148.

08. Huppertz B - Placental origins of preeclampsia: challenging the current hypothesis. Hypertension, 2008;51:970-975.

09. Valensise H, Vasapollo B, Gagliardi G et al. - Early and late preeclampsia: two different maternal hemodynamic states in the latent phase of the disease. Hypertension, 2008;52: 873-880.

10. Benedetti TJ, Cotton DB, Read JC et al. - Hemodynamic observations in severe pre-eclampsia with a flow-directed pulmonary artery catheter. Am J Obstet Gynecol, 1980;136:465-470.

11. Benedetti TJ, Kates R, Williams V - Hemodynamic observations in severe preeclampsia complicated by pulmonary edema. Am J Obstet Gynecol, 1985;152:330-334.

12. Sandham JD, Hull RD, Brant RF et al. - A randomized, controlled trial of the use of pulmonary artery catheters in high-risk surgical patients. N Engl J Med, 2003;348:5-14.

13. Dyer RA, James MF - Maternal hemodynamic monitoring in obstetric anesthesia. Anesthesiology, 2008;109:765-767.

14. Milsom I, Forssman L, Sivertsson R et al. - Measurement of cardiac stroke volume by impedance cardiography in the last trimester of pregnancy. Acta Obstet Gynecol Scand, 1983; 62:473-479.

15. Masaki DI, Greenspoon JS, Ouzounian JG - Measurement of cardiac output in pregnancy by thoracic electrical bioimpedance and thermodilution. A preliminary report. Am J Obstet Gynecol, 1989;161:680-684.

16. Easterling TR, Watts DH, Schmucker BC et al. - Measurement of cardiac output during pregnancy: validation of Doppler technique and clinical observations in preeclampsia. Obstet Gynecol, 1987;69:845850.

17. San-Frutos LM, Fernández $R$, Almagro $J$ et al. - Measure of hemodynamic patterns by thoracic electrical bioimpedance in normal pregnancy and in preeclampsia. Eur J Obstet Gynecol Reprod Biol, 2005;121:149-153.

18. Engoren M, Barbee D - Comparison of cardiac output determined by bioimpedance, thermodilution, and the Fick method. Am J Crit Care, 2005; 14:40-45.

19. Cheetah Medica - Bio-reactance. [Disponível em http://www.cheetah-medical.com/Bio-reactance].

20. Keren $H$, Burkhoff $D$, Squara $P$ - Evaluation of a non-invasive continuous cardiac output monitoring system based on thoracic bio-reactance. Am J Physiol Heart Circ Physiol, 2007;293:H583-589.

21. Squara $P$, Denjean $D$, Estagnasie $P$ et al. - Non-invasive cardiac output monitoring (NICOM): a clinical validation. Intensive Care Med, 2007;33:1191-1194.

22. Eckstein KL, Marx GF - Aortocaval compression and uterine displacement. Anesthesiology, 1974:40:92-96.

23. Kinsella SM, Whitwam JG, Spencer JAD - Aortic compression by the uterus: identification with the Finapres digital artery pressure instrument. Br J Obstet Gynaecol, 1990;97:700-705.

24. Swaminathan M, Phillips-Bute BG, Mathew JP - An assessment of two different methods of left ventricular ejection time measurement by transesophageal echocardiography. Anesth Analg, 2003;97:642-647.

\section{REFERÊNCIAS / REFERENCES}

01. Monga M - Maternal Cardiovascular, Respiratory and Renal Adaptation to Pregnancy, em: Creasy RK, Resnik R, lams JD et al. - Craesy and Resnik's Maternal Fetal Medicine: Principles and Practice. $6^{\text {th }}$ Ed, Philadelphia, Sauders Elsevier, 2009;101-109.

02. Metcalfe J, McAnulty JH, Ueland K - Cardiovascular physiology. Clin Obstet Gynecol, 1981; 24:693-710.

03. Leeman $L$, Fontaine $P-$ Hypertensive disorders of pregnancy. Am Fam Physician, 2008;78: 93-100.

04. Marik PE - Hypertensive disorders of pregnancy. Postgrad Med, 2009;121:69-76.

05. Khalil A, Jauniaux E, Harrington K - Antihypertensive therapy and central hemodynamics in women with hypertensive disorder in pregnancy. Obstet Gynecol, 2009;113:646-654.

25. Aronow WS, Bowter AF, Kaplan MA - External isovolemic contraction times and left ventricular ejection time/external isovolemic contraction time rations at rest and after exercise in coronary heart disease. Circulation, 1971;43:59-65.

26. Bromley PD, Hodges LD, Brodie DA - Physiological range of peak cardiac power output in healthy adults. Clin Physiol Funct Imaging, 2006;26:240-246

27. De Backer $D-$ Can passive leg raising be used to guide fluid administration? Crit Care, 2006;10:170-171.

28. Jabot J, Teboul JL, Richard C et al. - Passive leg raising for predicting fluid responsiveness: importance of the postural change. Intensive Care Med, 2009;35:85-90.

Resumen: Ohashi Y, Ibrahim H, Furtado L, Kingdom J, Carvalho JCA - Evaluación Hemodinámica no invasiva de mujeres no embaraza- 
das, embarazadas sanas y embarazadas con preeclampsia usando biorreactancia.

Justificativa y objetivos: Comparamos los perfiles hemodinámicos de embarazadas sanas y con preeclampsia ligera a término, como también los controles sanos de las no embarazadas, usando un nuevo monitor de débito cardíaco no invasivo (NICOM, del inglés), con base en la biorreactancia.

Métodos: Estudiamos embarazadas sanas a término (Embarazadas, $n=10$ ), embarazadas a término con preeclampsia ligera (EmbarazadasPE, $n=10$ ) y mujeres sanas no embarazadas (No Embarazadas, $n=10$ ). Con las pacientes en posición de semidecúbito lateral izquierdo, 4 electrodos del NICOM fueron colocados en la pared del tórax. Esa colocación fue secundada por un período de descanso de 15 minutos. Variables hemodinámicas, incluyendo presión arterial sistólica (PAS), diastólica (PAD) y promedio (PAM), como también la frecuencia cardíaca (FC), volumen sistólico (VS), resistencia periférica total (RPT), débito cardíaco (DC), potencia cardíaca (PC) y tiempo de eyección ventricular (TEV), fueron monitorizados por 15 minutos.
Resultados: Los grupos Embarazada y No Embarazada, presentaron perfiles hemodinámicos parecidos, excepto por un TEV más corto en el grupo Embar. (213,3 $\pm 19,3$ ms versus $265,0 \pm 28,8 \mathrm{~ms}$, $\mathrm{p}<0,001)$. El grupo Embar.PE presentó PAS, PAD y PAM más elevados, y PC (145,5 \pm 12,6 mmHg; 94,5 $\pm 9,1 \mathrm{mmHg} ; 111,5 \pm 9,8 \mathrm{mmHg}$; $1,6 \pm 0,3$ watts), cuando se comparó con los grupos Embar. (114 \pm $12,1 \mathrm{mmHg} ; 71,2 \pm 8,4 \mathrm{mmHg} ; 85,9 \pm 9,3 \mathrm{mmHg} ; 1,1 \pm 0,3$ watts) y No Embarazadas $(101,2 \pm 11,9 \mathrm{mmHg} ; 66,7 \pm 10,4 \mathrm{mmHg} ; 78,1$ $\pm 10,6 \mathrm{mmHg} ; 1,0 \pm 0,2$ watts). El grupo Embarazada presentó FC, DC y RPT más altos y TEV más corto $\left(85,4 \pm 8,4\right.$ latidos. $\min ^{-1} ; 6,6 \pm$ 0,7 L.min ${ }^{-1} ; 1.369,9 \pm 173,5$ dina.seg.cm ${ }^{5}, 221,6 \pm 22,4 \mathrm{~ms}$ ) cuando se le comparó con el grupo No Embarazadas (67,9 \pm 9,5 latidos.min-1; 5,6 \pm 0,7 L. $\mathrm{min}^{-1} ; 1.136,9 \pm 149,8$ dina.seg.cm ${ }^{5}, 265,0 \pm 28,8 \mathrm{~ms}$ ).

Conclusiones: EI NICOM es un equipo fácil de ser usado, que no depende del operador y que suministra señales de monitoreo claras y consistentes. La monitorización identificó perfiles hemodinámicos distintos y consistentes con los hallazgos de los métodos más invasivos existentes. 